\title{
Tratamento cirúrgico de estrabismo restritivo adquirido na infância: relato de caso
}

\author{
Surgical treatment of acquired restrictive strabismus in infancy: case report
}

Juliano Vescovi Damasceno ${ }^{1}$

Galton Carvalho Vasconcelos ${ }^{2}$

Ana Rosa Pimentel de Figueiredo ${ }^{3}$

Henderson Celestino de Almeida ${ }^{4}$

\section{RESUMO}

Os autores relatam um caso raro e grave de estrabismo restritivo, adquirido nos primeiros meses de vida, em criança previamente normal, com intenso acometimento da musculatura extraocular e tecidos adjacentes. Discutem a possibilidade de doença inflamatória ou infecciosa como causa etiológica. A dificuldade da abordagem cirúrgica do caso, descrita nos três procedimentos anteriores, foi resolvida na última cirurgia, pela cooperação de cirurgiões de estrabismo e órbita, utilizando-se incisão ampla para cirurgia orbitária.

Descritores: Estrabismo/cirurgia; Músculos oculomotores; Cicatriz; Órbita; Criança; Relatos de caso [Tipo de publicação]

\section{INTRODUÇÃOO}

A fibrose dos músculos extraoculares é caracterizada por limitação significativa das versões oculares, podendo ocorrer de forma congênita ou adquirida. Na forma congênita, sua apresentação clínica depende do número de músculos afetados e do grau de fibrose ${ }^{(1-2)}$. Raros são os casos de estrabismos restritivos por fibrose adquirida descritos na literatura ${ }^{(3-5)}$. Os autores relatam um caso de estrabismo por fibrose adquirida da musculatura extraocular, discutindo suas possíveis causas e a sua difícil abordagem cirúrgica.

Trabalho realizado nos Serviços de Estrabismo e Plástica Ocular do Hospital São Geraldo, Hospital das Clínicas da Universidade Federal de Minas Gerais - UFMG - Belo Horizonte (MG) - Brasil.

Residente de Oftalmologia do Hospital São Geraldo, Hospital das Clínicas da Universidade Federal de Minas Gerais - UFMG - Belo Horizonte (MG) - Brasil.

2 Doutor, Médico Assistente do Serviço de Estrabismo e Chefe do Serviço de Baixa Visão Infantil do Hospital São Geraldo, Hospital das Clínicas da UFMG - Belo Horizonte (MG) - Brasil.

${ }^{3}$ Doutora, Professora do Departamento de Oftalmologia da Faculdade de Medicina da UFMG e Chefe do Serviço de Plástica Ocular do Hospital São Geraldo, Hospital das Clínicas da UFMG - Belo Horizonte (MG) - Brasil.

${ }^{4}$ Professor Titular, Chefe do Serviço de Estrabismo do Hospital São Geraldo, Hospital das Clínicas da UFMG - Belo Horizonte (MG) - Brasil.

Endereço para correspondência: Juliano Vescovi Damasceno. Al. Vereador Álvaro Celso, 150 - Apto. 201 Belo Horizonte (MG) CEP 30150-260

E-mail: julianodamasceno@yahoo.com.br

Recebido para publicação em 29.01.2008

Aprovação em 30.11.2008

\footnotetext{
$\frac{\text { RELATO DO CASO }}{\text { Paciente do sexo masculino, gestação normal e parto difícil com fór- }}$ ceps e com desenvolvimento somatosensorial normal. Há história de prima com estrabismo. Segundo a mãe, aos dois meses de idade apresentou edema e hiperemia da pálpebra inferior esquerda, com resolução espontânea, porém com movimentos oculares normais. Aos cinco meses surgiu desvio no olhar à esquerda. Com um ano, o desvio aumentou bastante, permanecendo o olho esquerdo quase parado em adução e depressão, sendo o caso então admitido no serviço de estrabismo do Hospital São Geraldo da Universidade Federal de Minas Gerais (Figura 1A e B).

O exame apresentava hipotropia de 50 dioptrias prismáticas (DP) e esotropia de 30 DP no olho esquerdo pelo teste de Krimsky. Às versões, o olho direito estava normal e o olho esquerdo apresentava déficit acentuado da elevação e adução. A ducção forçada passiva mostrou forte restrição da elevação e abdução do olho esquerdo. Biomicroscopia, tonometria e fundoscopia estavam normais. Foram realizados três procedimentos cirúrgicos para se alcançar um resultado satisfatório.
} 
$\mathrm{Na}$ primeira cirurgia, com um ano e meio de idade, foi realizada a secção dos músculos retos medial e inferior esquerdos. Esses músculos no ato cirúrgico estavam muito aderidos à conjuntiva e com intensa fibrose. No seguimento, o olho esquerdo ficou congelado em adução (esotropia de 50 DP) e moderado hipotropia (30 DP). A tomografia computadorizada da órbita mostrou espessamento acentuado do músculo reto medial esquerdo (Figura 1C).

Na segunda cirurgia, com três anos e meio de idade, foi retirada significativa quantidade de tecido fibroso ao redor dos músculos reto medial e inferior, mas, mesmo assim, não se conseguiu abordar diretamente esses músculos.

O exame anatomopatológico demonstrou tecido fibroadiposo, com áreas de fibrose hialinizada (Figura 1D).
$\mathrm{Na}$ terceira cirurgia, aos seis anos de idade, optou-se por uma intervenção conjunta, envolvendo os serviços de estrabismo e plástica ocular. O procedimento iniciou-se por cantólise inferotemporal, acesso transconjuntival (cerca de $2 \mathrm{~mm}$ abaixo do bordo inferior do tarso) até o aspecto mais medial da pálpebra inferior, sob a porção canalicular. Na parte medial, havia fibrose densa, envolvendo completamente o ligamento capsulopalpebral e suas expansões para o retináculo medial, com aderências que aprisionavam os músculos reto inferior, reto medial e oblíquo inferior. Não era possível identificar apropriadamente as inserções esclerais dos músculos retos, estando possivelmente os corpos musculares envolvidos também pelo processo de cicatrização retrátil. Este conjunto de fibrose foi seccionado e o olho posicionado na

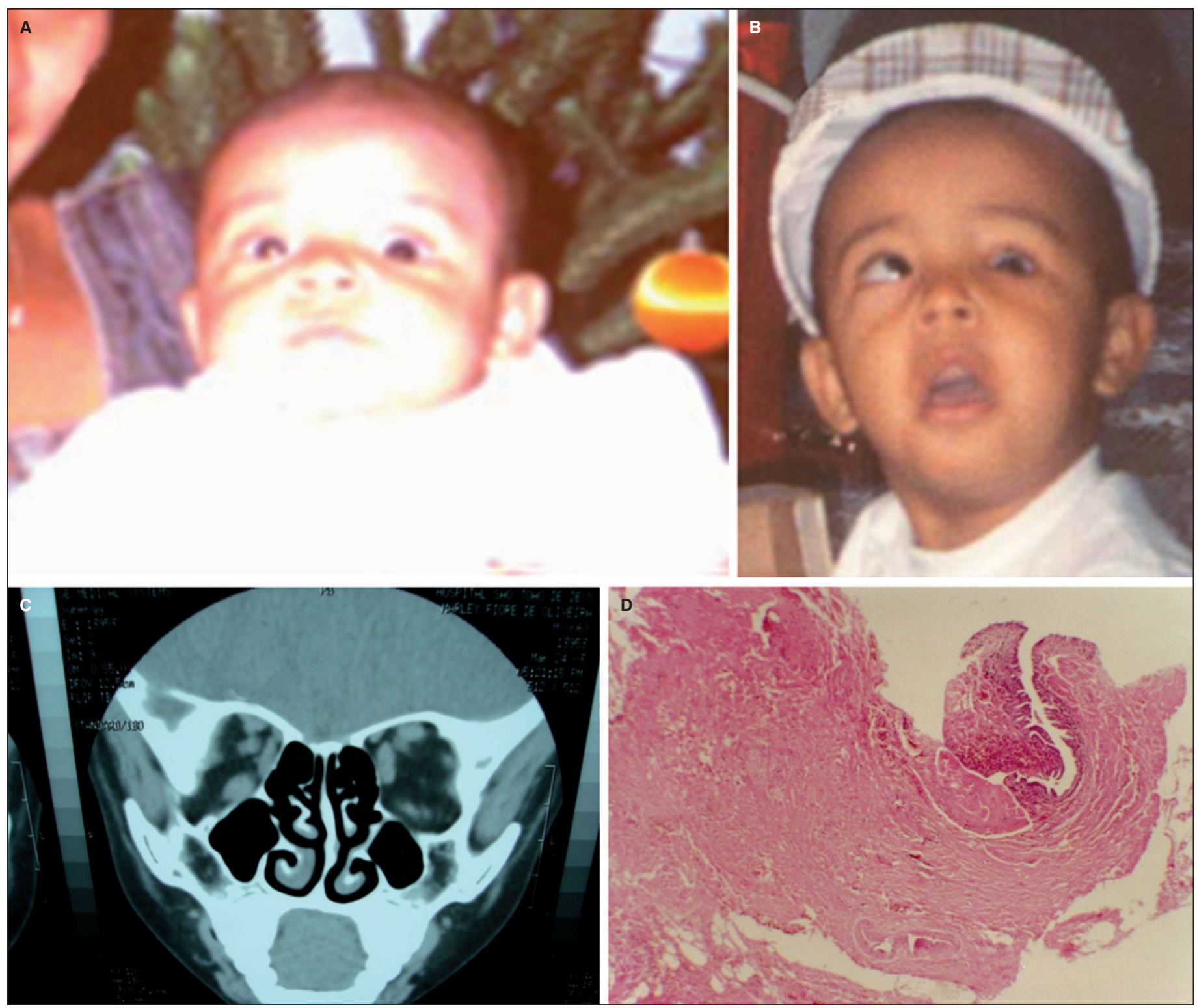

Figura 1 - A) paciente com dois meses de idade, antes do início do desvio; B) paciente com estrabismo após os cinco meses de idade; C) tomografia computadorizada de órbita com espessamento do músculo reto medial esquerdo; D) histopatológico com processo inflamatório inespecífico na órbita 
posição primaria do olhar. Toda a superfície ocular foi recoberta com membrana amniótica, uma vez que havia uma grande deficiência de conjuntiva em toda a porção palpebral, fórnice e porção bulbar de todo o quadrante medial inferior (Figura 2A e B).

Atualmente, com dez anos, o paciente apresenta acuidade visual no olho esquerdo de 20/800 (-3,50). Encontra-se com exotropia de $45 \mathrm{DP}$ e hipotropia de $16 \mathrm{DP}$, com o olho esquerdo congelado, com discreto movimento de depressão e pequeno simbléfaro inferior (Figura 2C e D).

\section{DISCUSSÃO}

Poucos são os casos de fibrose da musculatura extraocular adquirida nos primeiros meses de vida existentes na literatura médica, como relatado por Souza-Dias, et al. ${ }^{(3)}$.

Como causas de fibrose adquirida da musculatura extraocular figuram miosite, celulite orbitária ${ }^{(5)}$, orbitopatia de Gra- ves ${ }^{(6)}$ e até parasitoses, tais como miíase $\mathrm{e}^{(7-8)}$ e cisticercose ${ }^{(9)}$. Dentre estas, a mais comum é a miosite ${ }^{(6)}$. No presente caso, não se conseguiu identificar a causa básica da fibrose adjacente dos músculos. O processo inflamatório que a criança apresentou na pálpebra inferior esquerda, aos dois meses de idade, poderia, entre outras causas, dever-se a uma infecção bacteriana ou parasitária dos tecidos periorbitários.

A miíase orbitária é a forma mais rara da oftalmomiíase, representando $5 \%$ dos $\operatorname{casos}^{(8)}$. O parasita causa a necrose do tecido orbitário, podendo ocorrer uma infecção secundária ou mesmo uma intensa reação inflamatória associada ${ }^{(7)}$.

Há uma forte suspeita de que o caso se trate de uma míase com infecção secundária ou marcante reação inflamatória, não diagnosticada apropriadamente, uma vez que o paciente só se apresentou no serviço de estrabismo com um ano de idade. Após a resolução espontânea, resultou em cicatrização defeituosa de todo o compartimento inferomedial da órbita esquerda.
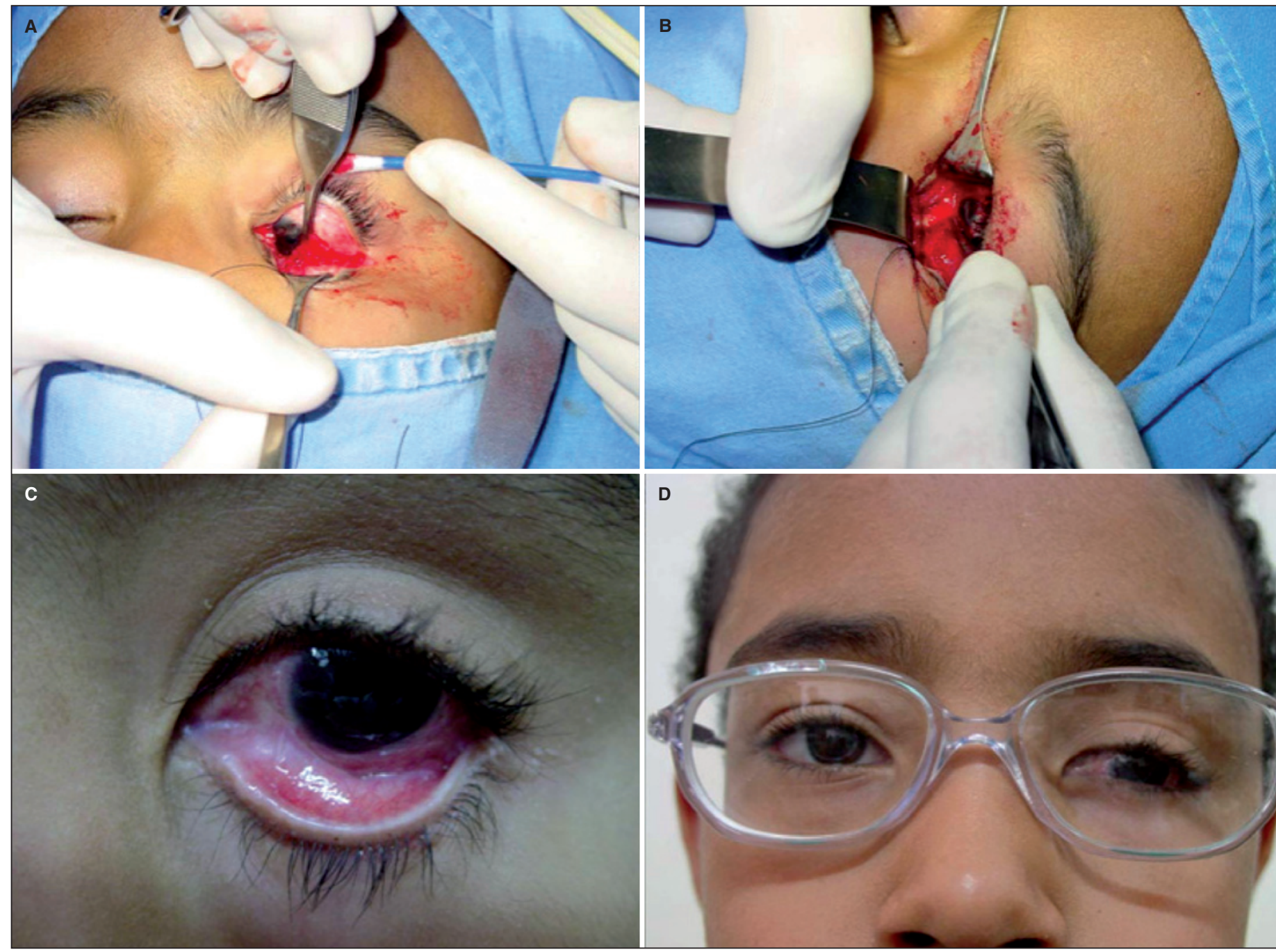

Figura 2 - (A e B) visão do per-operatório da terceira cirurgia realizada; (C e D) resultado final do paciente, com importante melhora do desvio e com pequeno simbléfaro na pálpebra inferior esquerda. 
A cisticercose orbitária é em geral unilateral, afetando músculos extraoculares, principalmente retos medial e inferior ${ }^{(9)}$. O diagnóstico é feito com a tomografia computadorizada da órbita, a ecografia B e exame de Elisa. No caso descrito não se dispunha de exame de Elisa para cisticercose e os achados tomográficos e ultrassonográficos foram negativos.

Em dois dos casos publicados por Souza-Dias et al. (3) houve ambliopia, sendo um com hipotropia e outro com esotropia, fato que condiz como o caso apresentado. Também houve a necessidade de duas intervenções cirúrgicas em dois desses casos relatados, realçando a dificuldade de abordagem cirúrgica desta doença.

Devido à complexidade desse tipo de caso, por ter alto potencial ambliopigênico e a dificuladade do tratamento cirúrgico, é de fundamental importância a avaliação conjunta e multidisciplinar entre estrabólogos e cirurgiões de órbita desde o início do processo, visando a um melhor resultado funcional e estético, com a menor exposição possível do paciente a procedimentos cirúrgicos.

\section{ABSTRACT}

The authors describe a severe and rare case of restrictive strabismus, acquired during the first semester of life, in a previously normal baby. They discuss the possibility of in- flammatory or infectious disease as the primary cause. Surgical management was challenging, after three procedures and required the cooperation of strabismus and orbit specialists and also a wide incision for orbital surgery.

Keywords: Strabismus/surgery; Oculomotor muscles; Cicatrix; Orbit; Child; Case reports [Publication type]

\section{REFERÊNCIAS}

1. Yazdani A, Traboulsi EI. Classification and surgical management of patients with familial and sporadic forms of congenital fibrosis of the extraocular muscles. Ophthalmology. 2004;111(5):1035-42.

2. Harley RD, Rodrigues MM, Crawford JS. Congenital fibrosis of the extraocular muscles. Trans Am Ophthalmol Soc. 1978;76:197-226.

3. Souza-Dias C, Scott AB, Wang AH. Progressive restrictive strabismus acquired in infancy. Br J Ophthalmol. 2005;89(8):986-7.

4. Jain S, Goulstine D, Gottlob I. Acute adduction deficit in a 7-week-old infant. Strabismus. 2002;10(4):241-4.

5. Kang KD, Kang SM, Yim HB. Acute acquired comitant esotropia after orbital cellulitis. J AAPOS. 2006;10(6):581-2.

6. Chan W, Wong GW, Fan DS, Cheng AC, Lam DS, Ng JS. Ophthalmopathy in childhood Graves' disease. Br J Ophthalmol. 2002;86(7):740-2.

7. Caça I, Unlü K, Cakmak SS, Bilek K, Sakalar YB, Unlü G. Orbital myiasis: case report. Jpn J Ophthalmol. 2003;47(4):412-4.

8. Baliga MJ, Davis P, Rai P, Rajasekhar V. Orbital myiasis: a case report. Int J Oral Maxillofac Surg. 2001;30(1):83-4.

9. Pushker N, Bajaj MS, Chandra M, Neena. Ocular and orbital cysticercosis. Acta Ophthalmol Scand. 2001;79(4):408-13. 